2010

\title{
Light Attenuation at Molasses Reef
}

Ashley Earls

University of South Florida

Advisors:

Arcadii Grinshpan, Mathematics and Statistics

Pamela Hallock-Muller, Biological Oceanography

Problem Suggested By: Chuanmin Hu

Field of Study for Problem Suggester: Optical Oceanography

Follow this and additional works at: https://digitalcommons.usf.edu/ujmm

Part of the Mathematics Commons

UJMM is an open access journal, free to authors and readers, and relies on your support:

Donate Now

\section{Recommended Citation}

Earls, Ashley (2010) "Light Attenuation at Molasses Reef," Undergraduate Journal of Mathematical

Modeling: One + Two: Vol. 3: Iss. 1, Article 8.

DOI: http://dx.doi.org/10.5038/2326-3652.3.1.20

Available at: https://digitalcommons.usf.edu/ujmm/vol3/iss1/20 


\title{
Light Attenuation at Molasses Reef
}

\begin{abstract}
Estimating the amount of light available at different depths of the ocean is important for gaining a better understanding of coral reefs. It is especially useful to be able to get such estimates without having to perform direct measurements. Although accurate, the direct measurements are costly, time consuming, and usually limited to relatively small areas of interest.

One statistic that could be useful for estimating the amount of available light is the rate at which it declines with depth (the rate of light attenuation). In this project, this rate is calculated for four different wavelengths using data for $30 \mathrm{~m}$ water column profile collected in upper Florida Keys. The rate of light attenuation is calculated for the entire profile as well as the intervals corresponding to $5 \mathrm{~m}$ increments.
\end{abstract}

\section{Keywords}

Available Light, Rate of Light Decline, Coral Reef

Creative Commons License

(c) (i) $(9)$

This work is licensed under a Creative Commons Attribution-Noncommercial-Share Alike 4.0 License.

\section{Erratum}

This article was previously called Article 20. 


\section{TABLE OF CONTENTS}

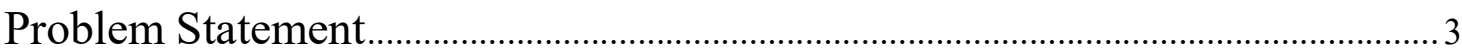

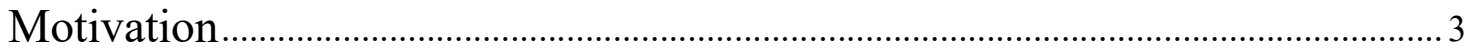

Mathematical Description and Solution Approach ................................................. 3

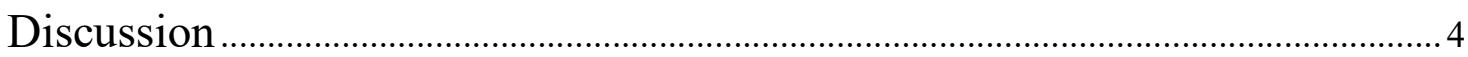

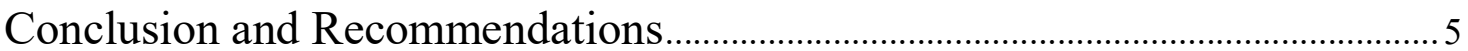

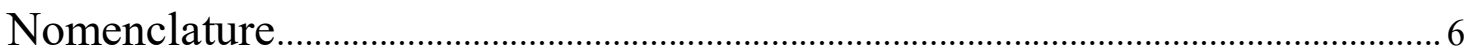

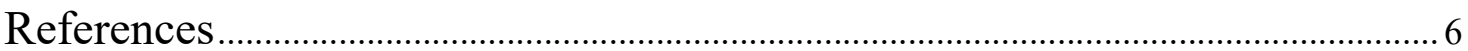

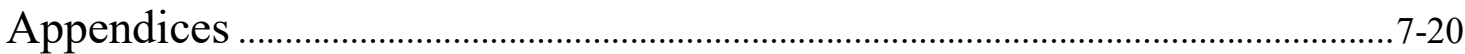




\section{PROBLEM STATEMENT}

Estimate the rate of light decline for each wavelength for the following intervals:
a) Surface $(0 \mathrm{~m})$ to $30 \mathrm{~m}$
b) Surface (0m) to $5 \mathrm{~m}$ (downward)
c) $5 \mathrm{~m}$ to $10 \mathrm{~m}$
d) $10 \mathrm{~m}$ to $15 \mathrm{~m}$
e) $15 \mathrm{~m}$ to $20 \mathrm{~m}$
f) $20 \mathrm{~m}$ to $25 \mathrm{~m}$
g) $25 \mathrm{~m}$ to $30 \mathrm{~m}$

Repeat b) through g) for the upward profile. Discuss any differences you see in the rates that you calculated.

\section{Motivation}

The amount of light available at certain depths has a significant effect on the organisms in the area (Hallock-Muller). Photosynthetic organisms, such as various reef inhabitants and benthic algae need a specific amount of light to survive. Furthermore, the amount of available light could affect survival rates or success rates in photosynthetic mutualisms (Hallock and Schlager).

The objective of this project is to estimate the rate of light attenuation over different depth intervals. This is achieved using the data quantifying the amount of available light for four different wavelengths at depths ranging from the surface $(0 \mathrm{~m})$ to the benthic zone $(30 \mathrm{~m})$ of Molasses Reef located near the Florida Keys. 


\section{MATHEMATICAL DESCRIPTION AND SOLUTION APPROACH}

One possible way to calculate the rate of light attenuation is to first fit a function to the data and then find the derivative of this function with respect to the depth. Because the plot of the amount of available light with respect to height suggests exponential decay (see Fig. 1), the data is fitted to the function

$$
f(x)=C e^{-k x}
$$

where $f(x)$ is the amount of available light, $C$ is a constant, $k$ is the rate of decline, and $x$ is the depth. The rate of decline of $f(x)=C e^{-k x}$ is given by its derivative $f^{\prime}(x)=-C k e^{-k x}$. Thus instead of explicitly stating $f(x)$ and $f^{\prime}(x)$ for each interval and each wavelength it is convenient to simply give the corresponding values of $C$ and $k$.

\section{DISCUSSION}

Appendix-Tables contains a summary of all our calculations. As pointed out in the previous section, instead of giving a function representing the amount of light and the rate of light attenuation (derivative) on a given interval, we simply state the corresponding values of $C$ and $k$. The graphs of these functions can be found in Appendix-Figures.

The amount of light with $305 \mathrm{~nm}$ and $330 \mathrm{~nm}$ wavelengths seems to decline faster than the 380nm and PAR light (see Fig. 1). This suggests that most of the light at these wavelengths is absorbed at relatively small depths. The spike in the amount of available light between $15 \mathrm{~m}$ and $20 \mathrm{~m}$ in the downward profile (see Fig. 5) seems abnormal. Because it is not present on the upward profile, it is probably a sensor malfunction. The other discrepancies in the amount of available light between upward and downward profiles can be contributed to (1) differences in coverage of each interval and (2) changes in the sunlight intensity. 


\section{CONCLUSION AND RECOMMENDATIONS}

Using the surface to $30 \mathrm{~m}$ profile, we have calculated the rate of attenuation by taking the derivative of the function of the best fit:

- $g_{1}(x)=1.03 e^{-0.17 x} \mu \mathrm{W} / \mathrm{cm}^{2} / \mathrm{nm} / \mathrm{m}$ for the light with $305 \mathrm{~nm}$ wavelength,

- $g_{2}(x)=3.37 e^{-0.08 x} \mu \mathrm{W} / \mathrm{cm}^{2} / \mathrm{nm} / \mathrm{m}$ for the light with $330 \mathrm{~nm}$ wavelength,

- $g_{3}(x)=1.77 e^{-0.03 x} \mu \mathrm{W} / \mathrm{cm}^{2} / \mathrm{nm} / \mathrm{m}$ for the light with $380 \mathrm{~nm}$ wavelength,

- $g_{4}(x)=58.91 e^{-0.05 x} \mu \mathrm{E} / \mathrm{m}^{2} / \mathrm{s} / \mathrm{m}$ for the light with PAR wavelength,

where $x$ is the depth.

It is likely that these estimates are more reliable than those for many $5 \mathrm{~m}$ intervals. This is because a cluster of outliers in a $5 \mathrm{~m}$ interval affects its estimated rate of attenuation significantly more than the rate of attenuation for the entire profile.

The rates of light attenuation observed on $15 \mathrm{~m}-20 \mathrm{~m}$ (downward profile), surface-5m (upward profile) intervals for the light with wavelength $380 \mathrm{~nm}$ and on $15 \mathrm{~m}-20 \mathrm{~m}$ (upward profile) interval for PAR wavelength are probably due to the sensor malfunction. The unusual spike in the amount of available light on $15 \mathrm{~m}-20 \mathrm{~m}$ (downward profile) interval has distorted the rates of light attenuation for all four wavelengths.

It may be possible to avoid these problems by preprocessing the data after its collection by removing the values having a high probability of being erroneous. 


\section{NOMENCLATURE}

\begin{tabular}{|cll|}
\hline Symbol & Description & Units \\
\hline$x$ & Depth & Meters \\
\hline$f(x)$ & Amount of available light at depth $x$ & $\begin{array}{l}\mu \mathrm{E} / \mathrm{m}^{2} / \mathrm{s} \text { PAR wavelength } \\
\mu \mathrm{W} / \mathrm{cm}^{2} / \mathrm{nm} \text { for other wavelengths }\end{array}$ \\
\hline$g(x)$ & Rate of light attenuation at depth $x$ & $\begin{array}{l}\mu \mathrm{E} / \mathrm{m}^{2} / \mathrm{s} / \mathrm{m} \text { for PAR wavelength } \\
\mu \mathrm{W} / \mathrm{cm}^{2} / \mathrm{nm} / \mathrm{m} \text { for other wavelengths: }\end{array}$ \\
\hline$k$ & Rate of decay & $\mathrm{n} / \mathrm{a}$ \\
\hline$C$ & Constant & $\mathrm{n} / \mathrm{a}$ \\
\hline
\end{tabular}

\section{REFERENCES}

Hallock, Pamela and Schlager, Wolfgang. "Nutrient Excess and the Demise of Coral Reefs and Carbonate Plateforms." PALAIOS (1986): 389-398.

Hallock-Muller, Pamela. "Light Measurements at Molasses Reef." 2005. 


\section{APPENDIX I - FIGURES}

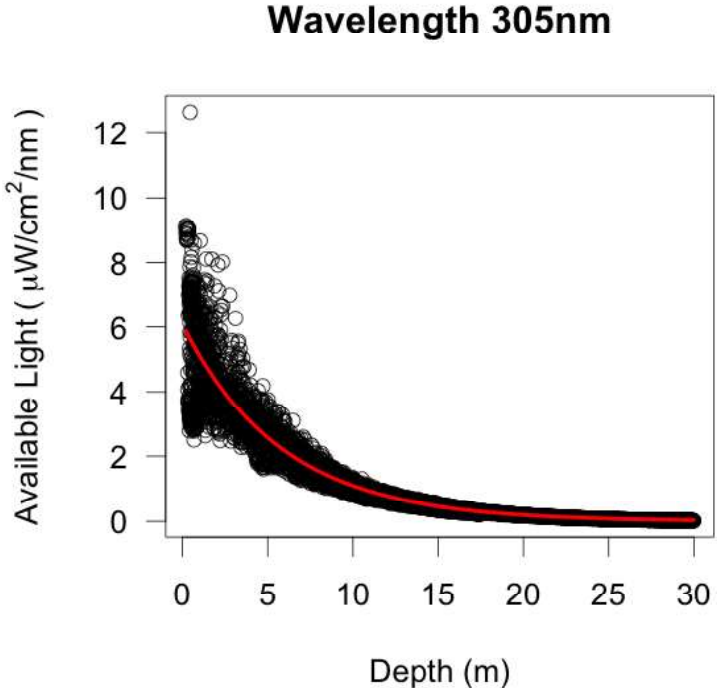

Wavelength $380 \mathrm{~nm}$

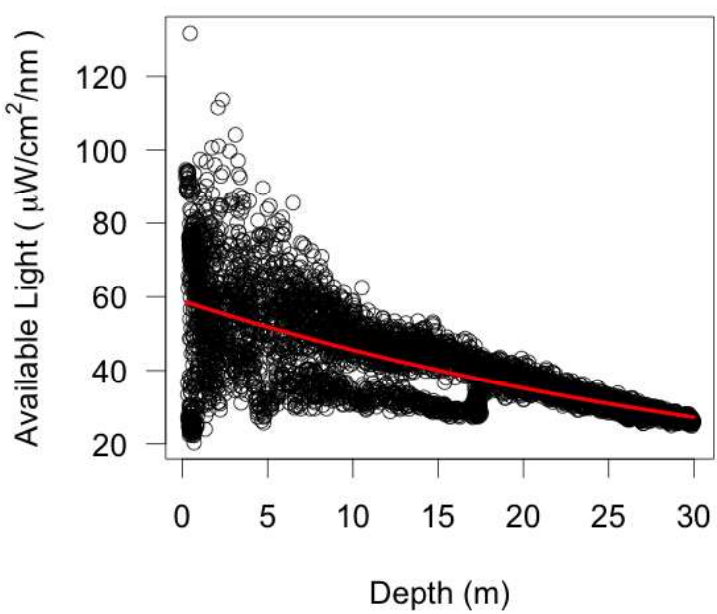

Wavelength 330nm

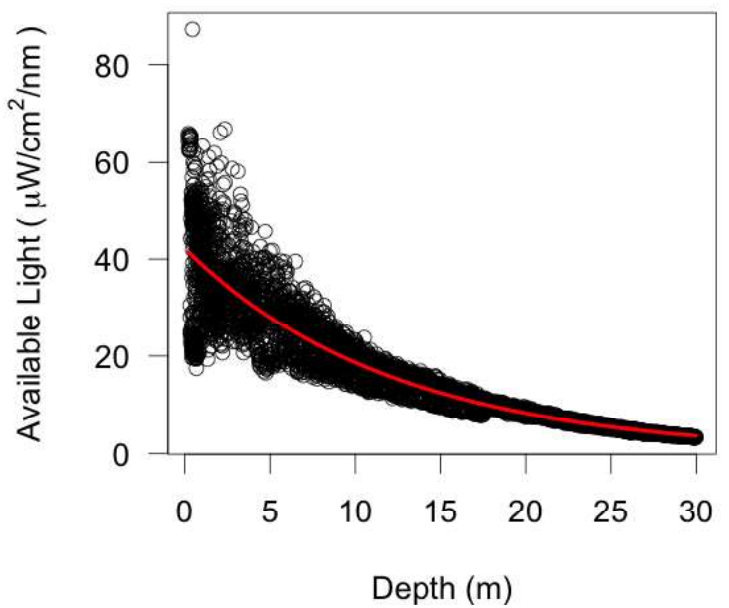

PAR

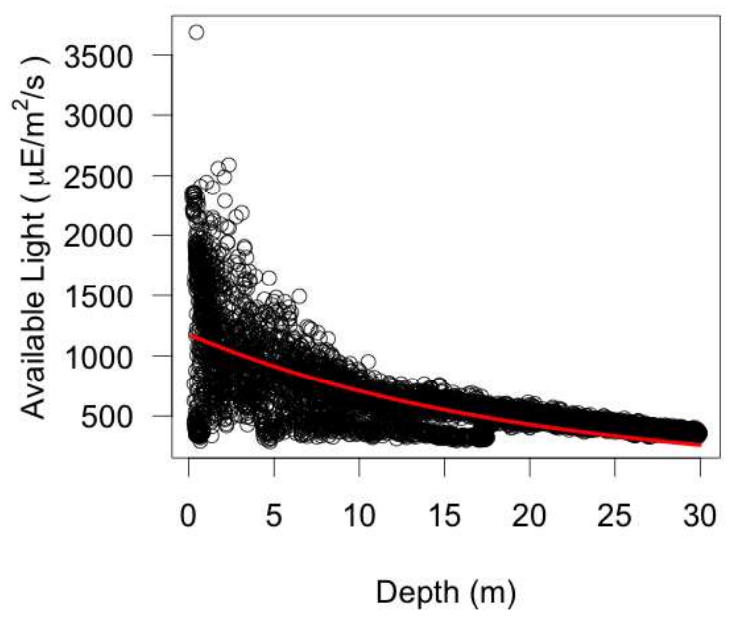

Figure 1: The amount of available light in surface to $30 \mathrm{~m}$ interval with the curve of the best fit depicted in red. The $(C, k)$ values are $(6.08,0.17)$ for $305 \mathrm{~nm},(42.16,0.08)$ for $330 \mathrm{~nm},(58.87,0.03)$ for $380 \mathrm{~nm}$, and $(1178.11,0.05)$ for PAR. 


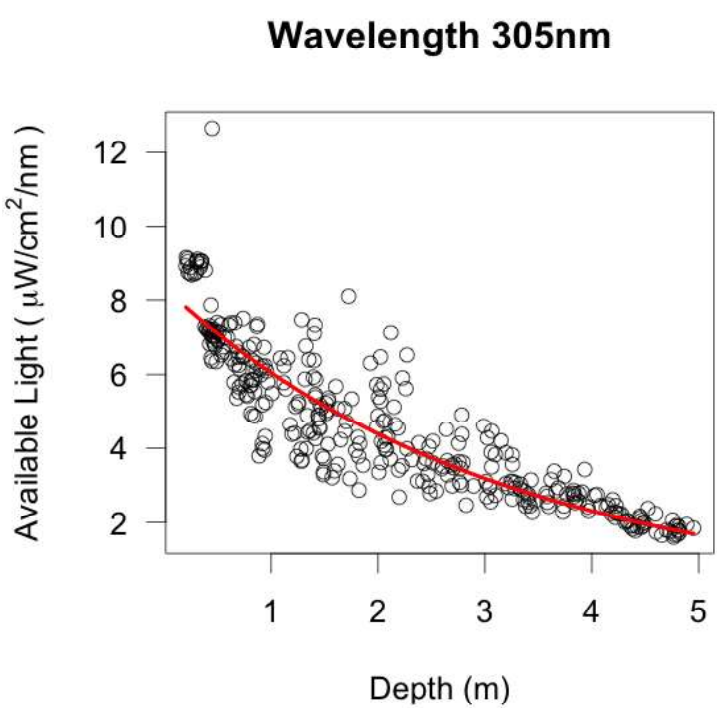

Wavelength $380 \mathrm{~nm}$

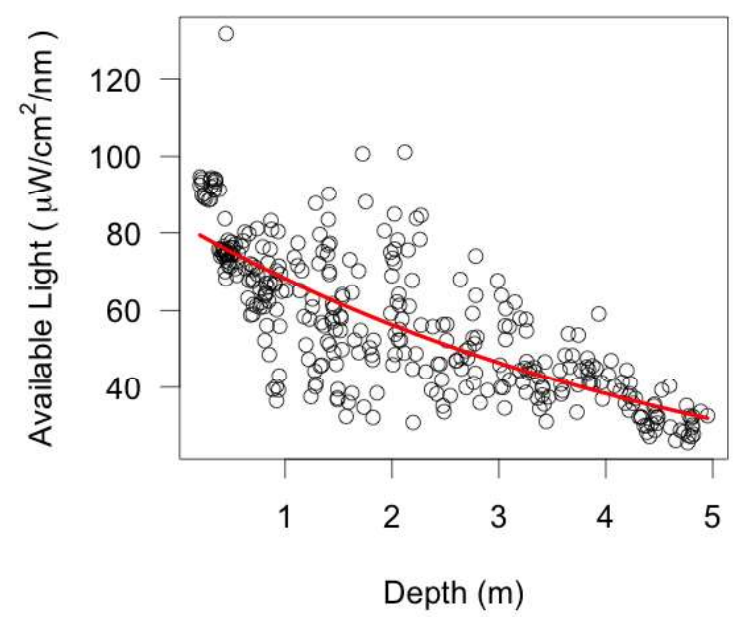

Wavelength $330 \mathrm{~nm}$

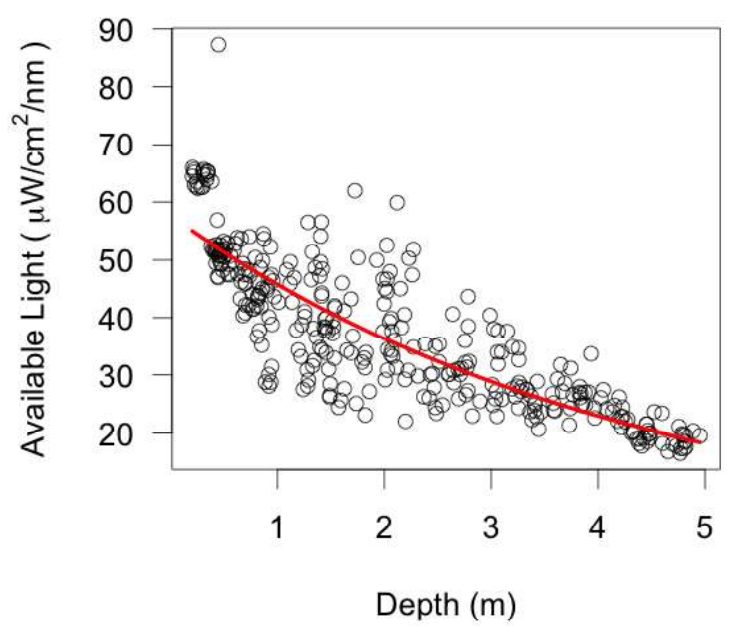

PAR

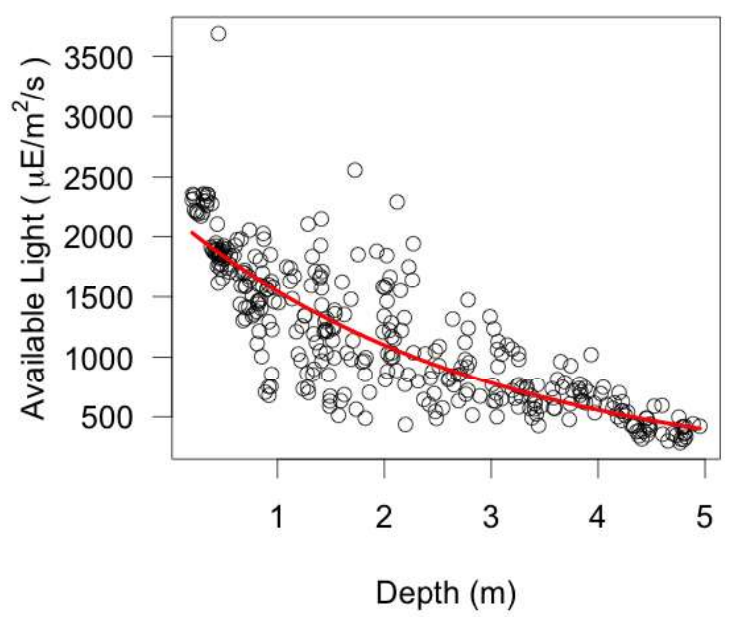

Figure 2: The amount of available light in surface to $5 \mathrm{~m}$ interval (downward profile) with the curve of the best fit depicted in red. The $(C, k)$ values are $(8.34,0.32)$ for $305 \mathrm{~nm},(57.62,0.23)$ for $330 \mathrm{~nm},(82.58,0.19)$ for $380 \mathrm{~nm}$, and $(2174.78,0.34)$ for PAR. 


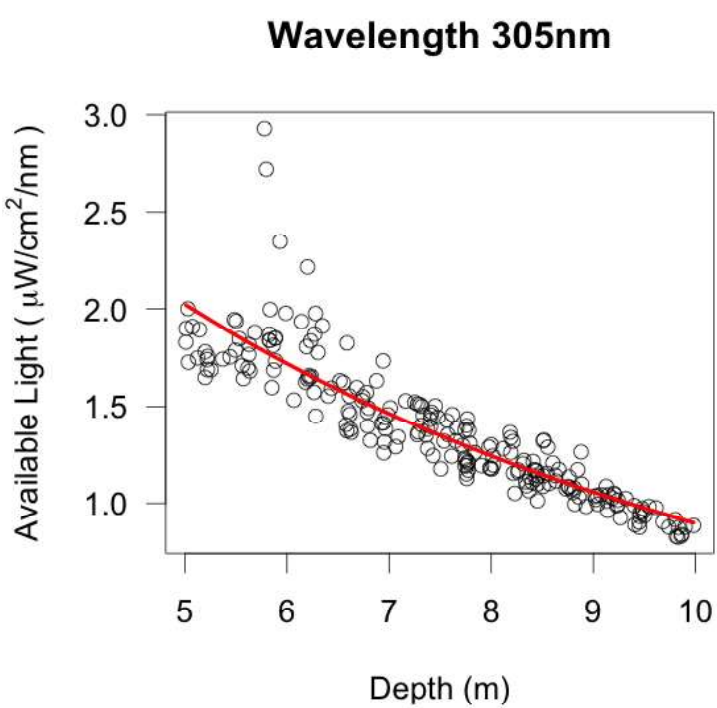

Wavelength $380 \mathrm{~nm}$

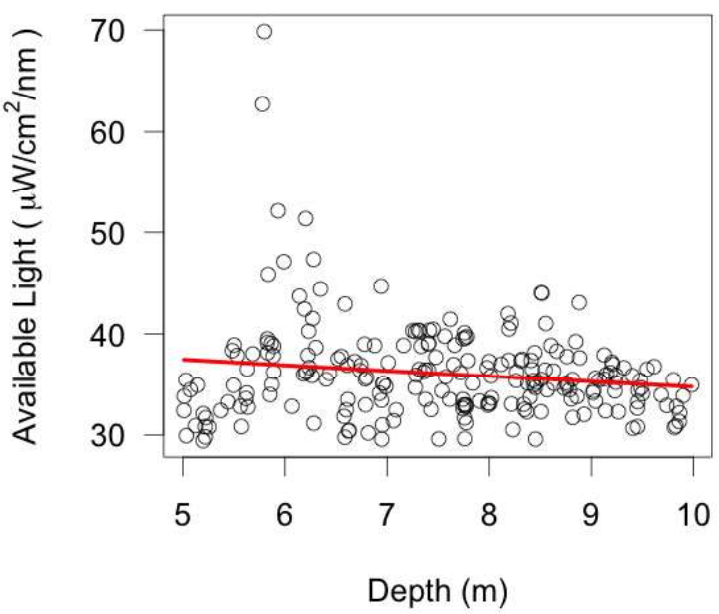

Wavelength 330nm

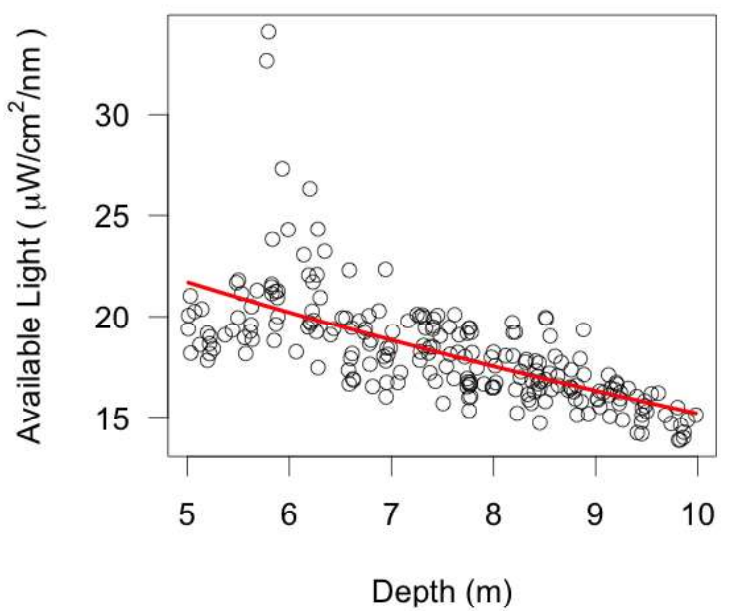

PAR

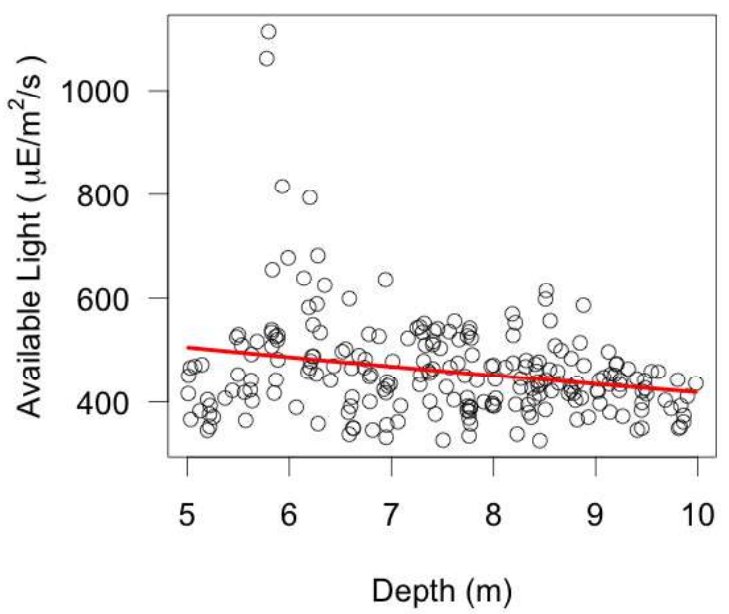

Figure 3: The amount of available light in $5 \mathrm{~m}$ to $10 \mathrm{~m}$ interval (downward profile) with the curve of the best fit depicted in red. The $(C, k)$ values are $(4.56,0.16)$ for $305 \mathrm{~nm},(31.00,0.07)$ for $330 \mathrm{~nm}$, $(40.44,0.02)$ for $380 \mathrm{~nm}$, and $(611.70,0.04)$ for PAR. 
Wavelength $305 \mathrm{~nm}$

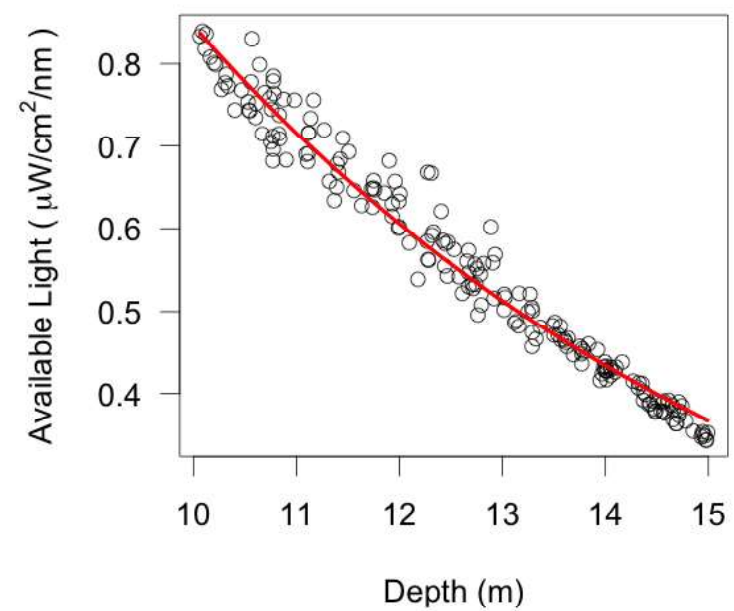

Wavelength 380nm

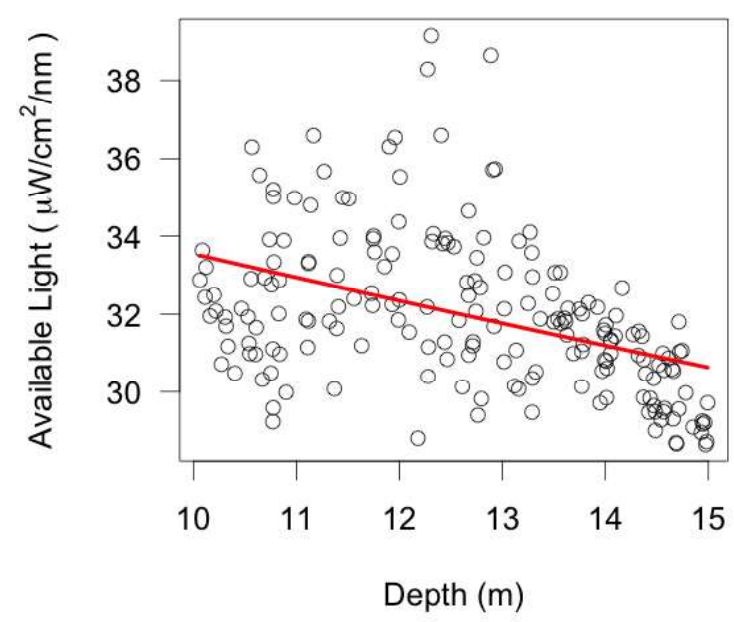

Wavelength $330 \mathrm{~nm}$

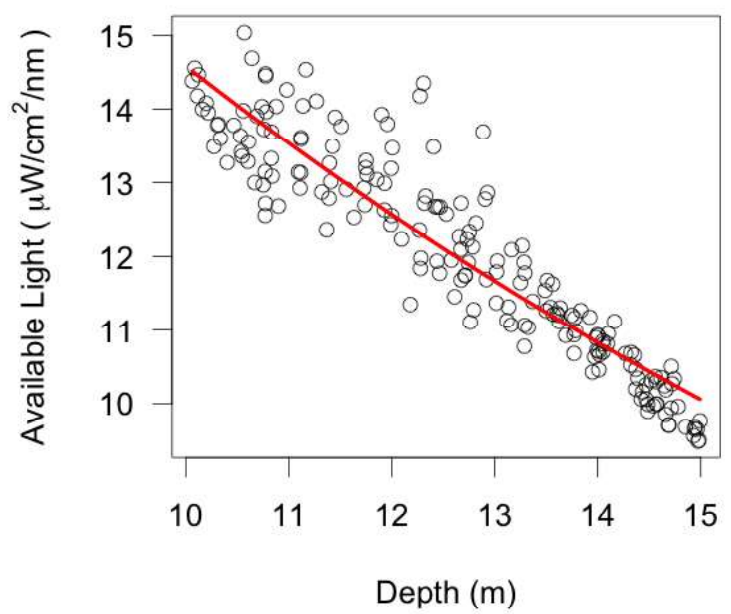

PAR

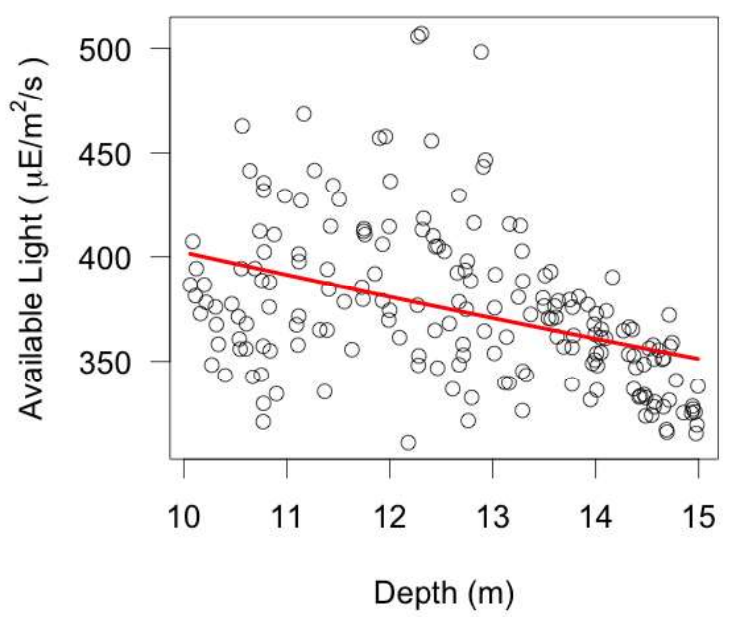

Figure 4: The amount of available light in $10 \mathrm{~m}$ to $15 \mathrm{~m}$ interval (downward profile) with the curve of the best fit depicted in red. The $(C, k)$ values are $(4.49,0.17)$ for $305 \mathrm{~nm},(30.68,0.07)$ for $330 \mathrm{~nm}$, $(40.19,0.02)$ for $380 \mathrm{~nm}$, and $(526.11,0.03)$ for PAR. 
Wavelength $305 \mathrm{~nm}$

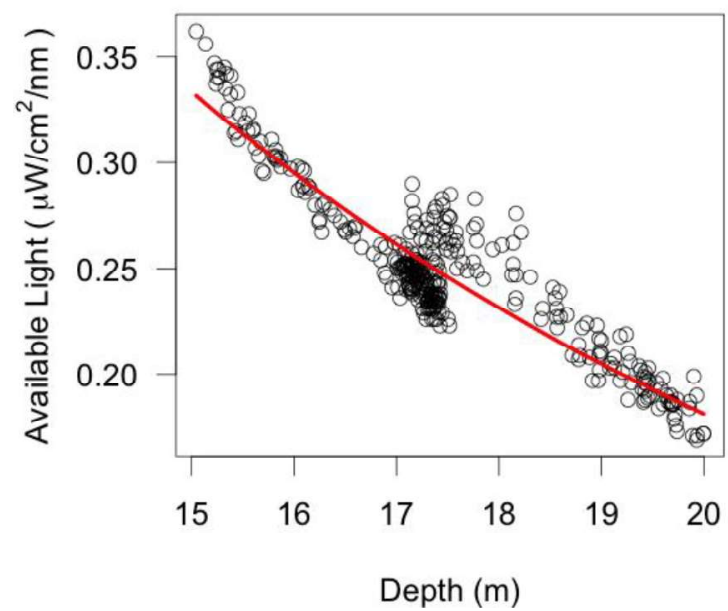

Wavelength 380nm

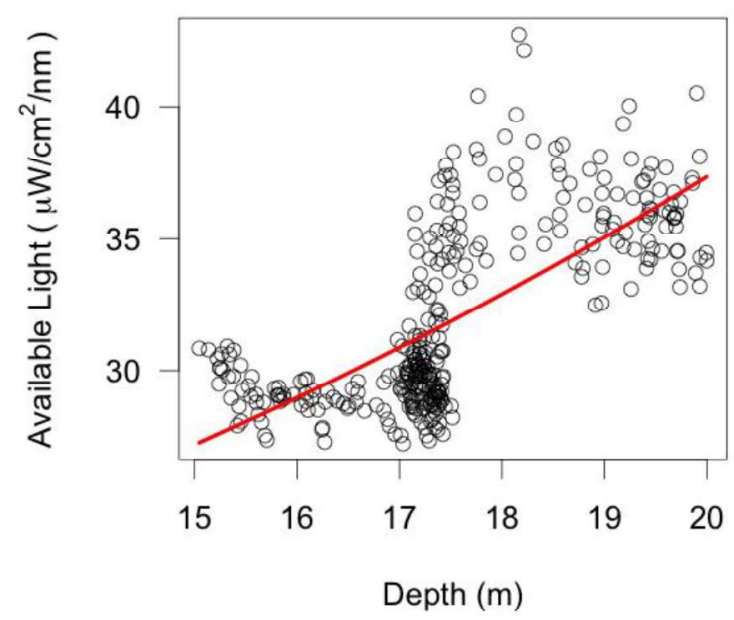

Wavelength $330 \mathrm{~nm}$

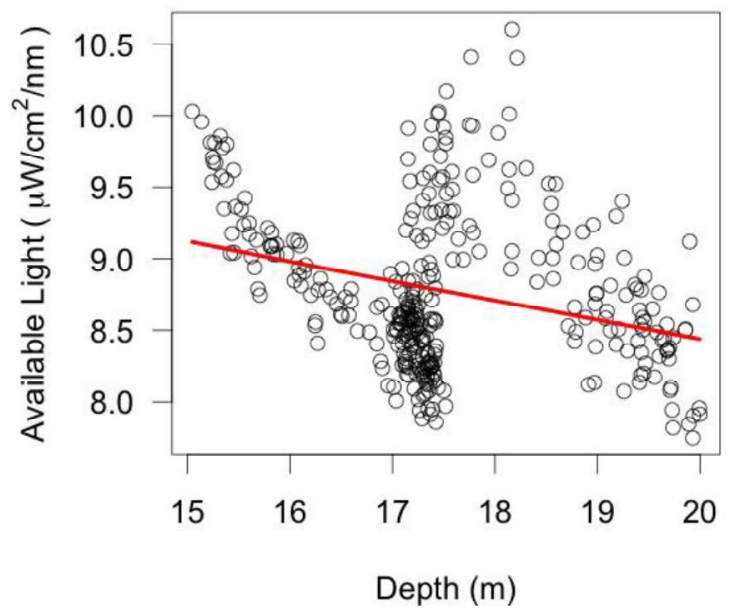

PAR

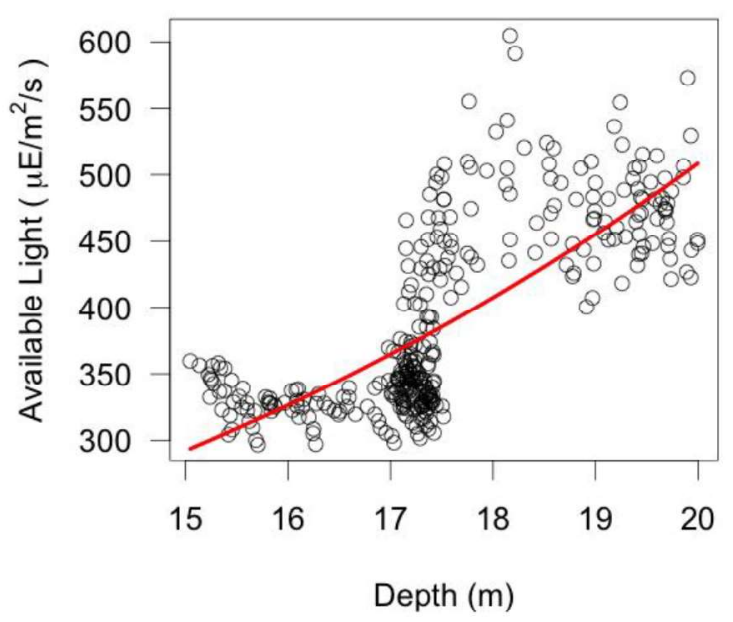

Figure 5: The amount of available light in $15 \mathrm{~m}$ to $20 \mathrm{~m}$ interval (downward profile) with the curve of the best fit depicted in red. The $(C, k)$ values are $(2.07,0.12)$ for $305 \mathrm{~nm},(11.51,0.02)$ for $330 \mathrm{~nm}$, $(10.47,0.06)$ for $380 \mathrm{~nm}$, and $(55.37,0.11)$ for PAR. 
Wavelength $305 \mathrm{~nm}$

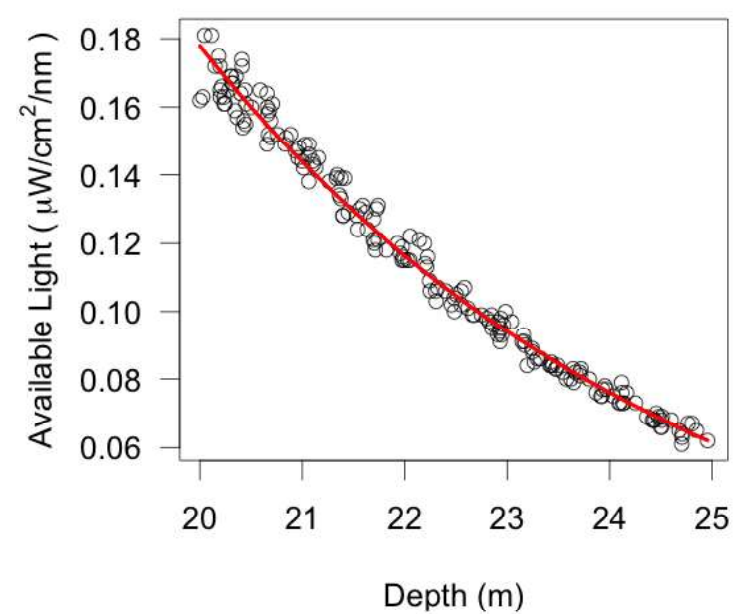

Wavelength 380nm

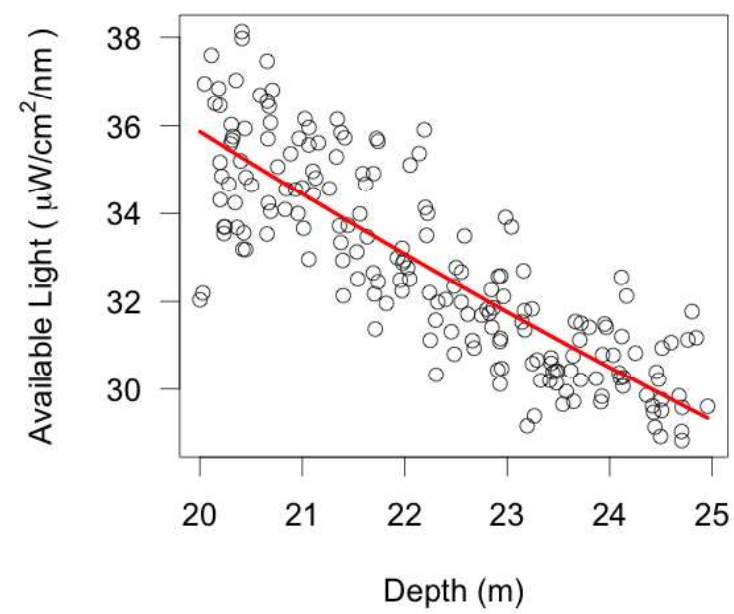

Wavelength $330 \mathrm{~nm}$

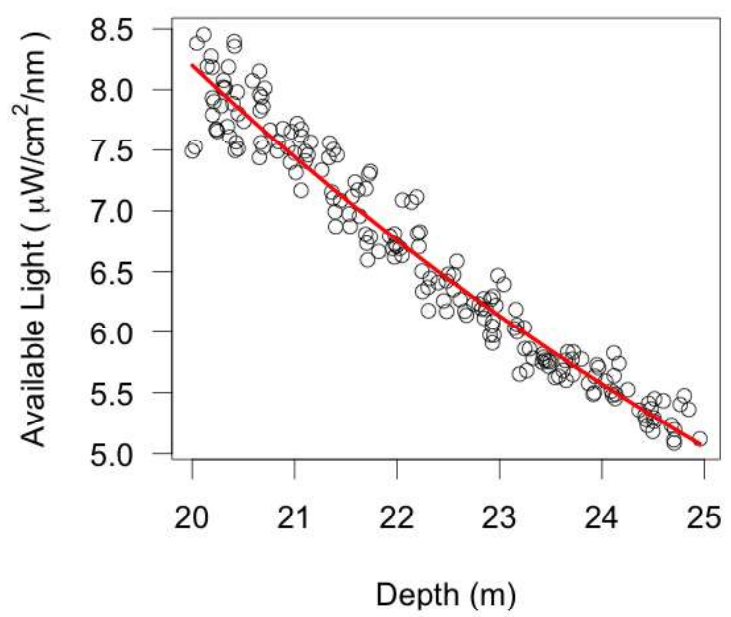

PAR

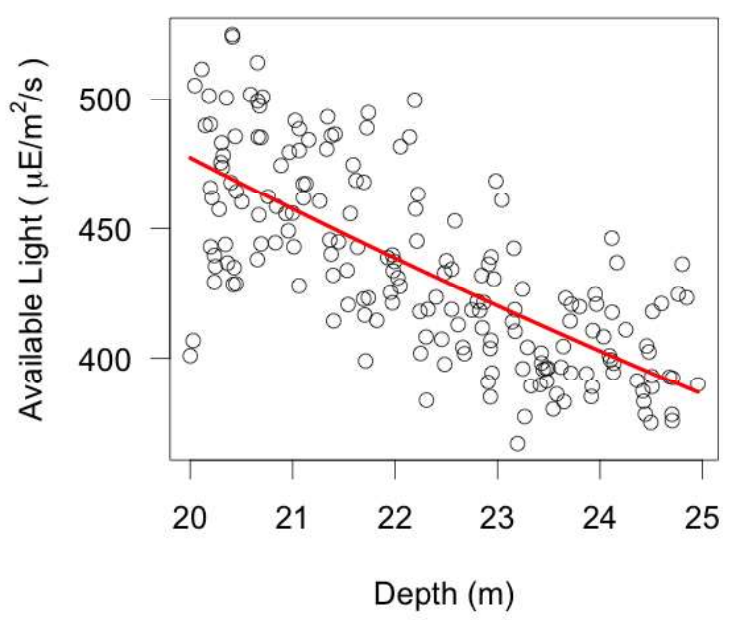

Figure 6: The amount of available light in $20 \mathrm{~m}$ to $25 \mathrm{~m}$ interval (downward profile) with the curve of the best fit depicted in red. The $(C, k)$ values are $(12.50,0.21)$ for $305 \mathrm{~nm},(56.60,0.10)$ for $330 \mathrm{~nm},(80.67,0.04)$ for $380 \mathrm{~nm}$, and $(1119.07,0.04)$ for PAR. 
Wavelength $305 \mathrm{~nm}$

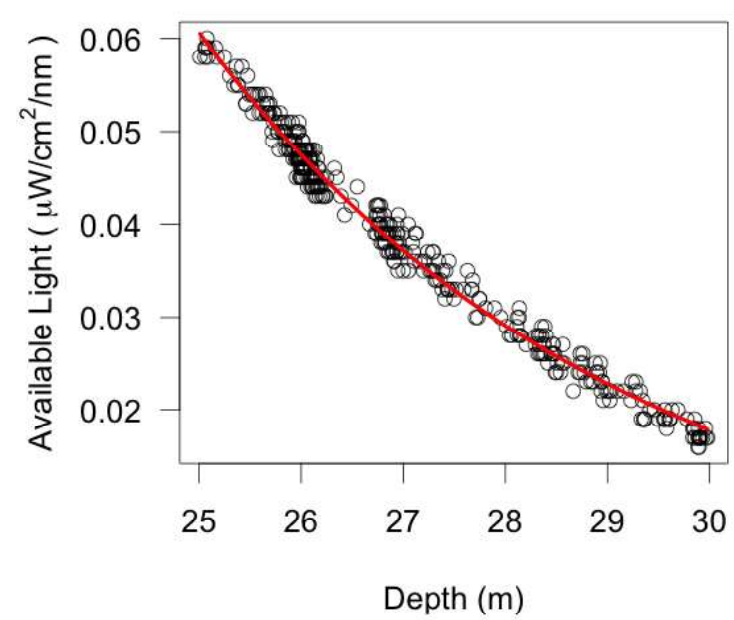

Wavelength 380nm

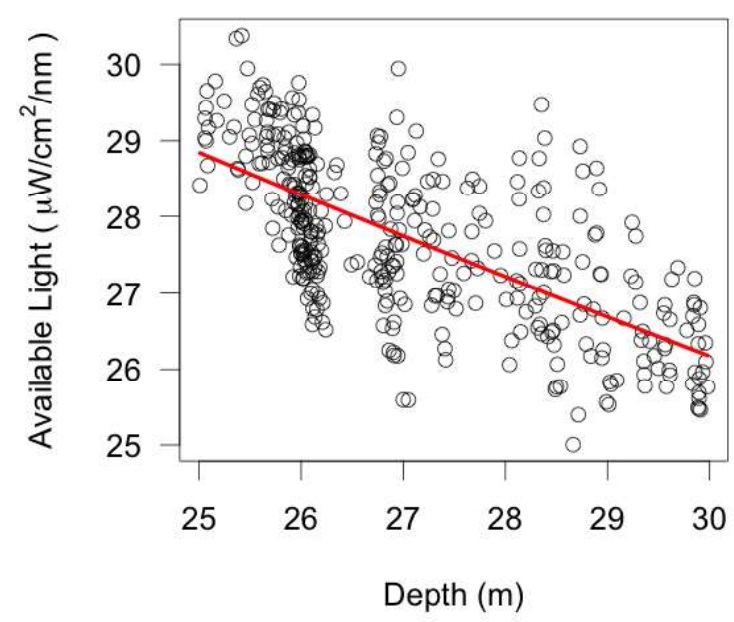

Wavelength $330 \mathrm{~nm}$

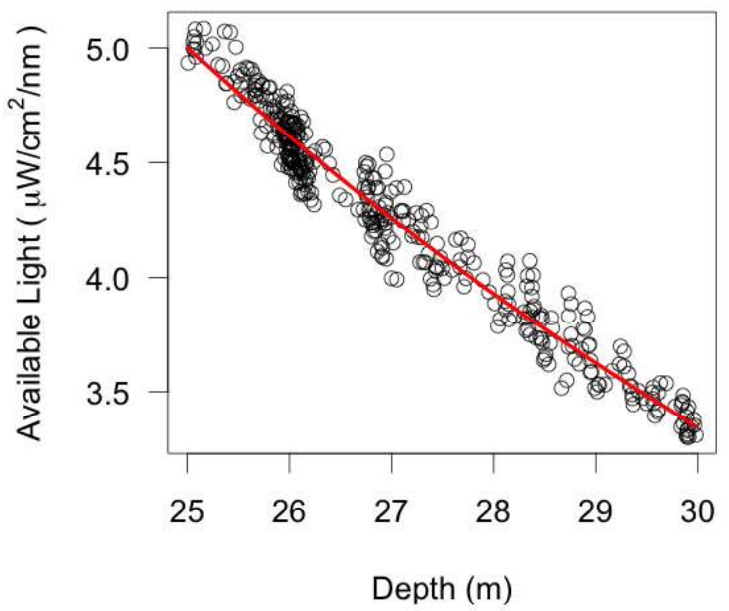

PAR

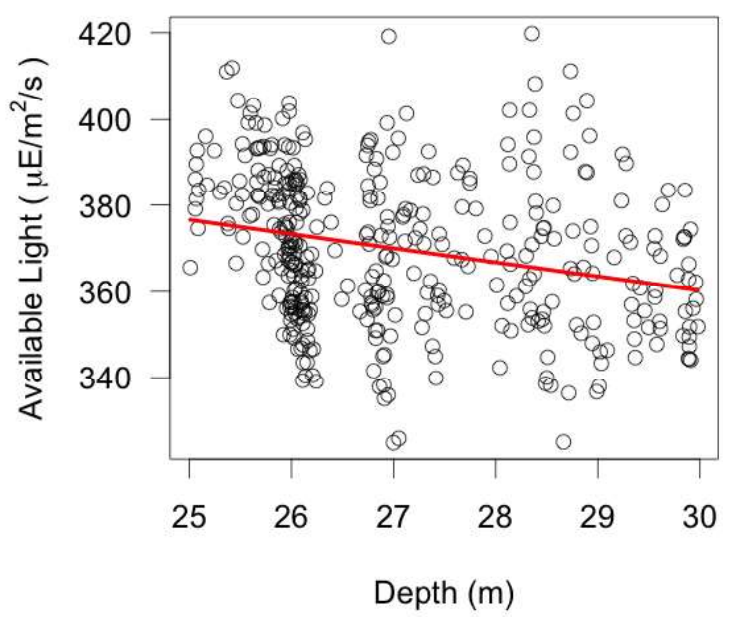

Figure 7: The amount of available light in $25 \mathrm{~m}$ to $30 \mathrm{~m}$ interval (downward profile) with the curve of the best fit depicted in red. The $(C, k)$ values are $(27.57,0.24)$ for $305 \mathrm{~nm},(37.43,0.08)$ for $330 \mathrm{~nm},(46.91,0.02)$ for $380 \mathrm{~nm}$, and $(229.54,0.01)$ for PAR. 

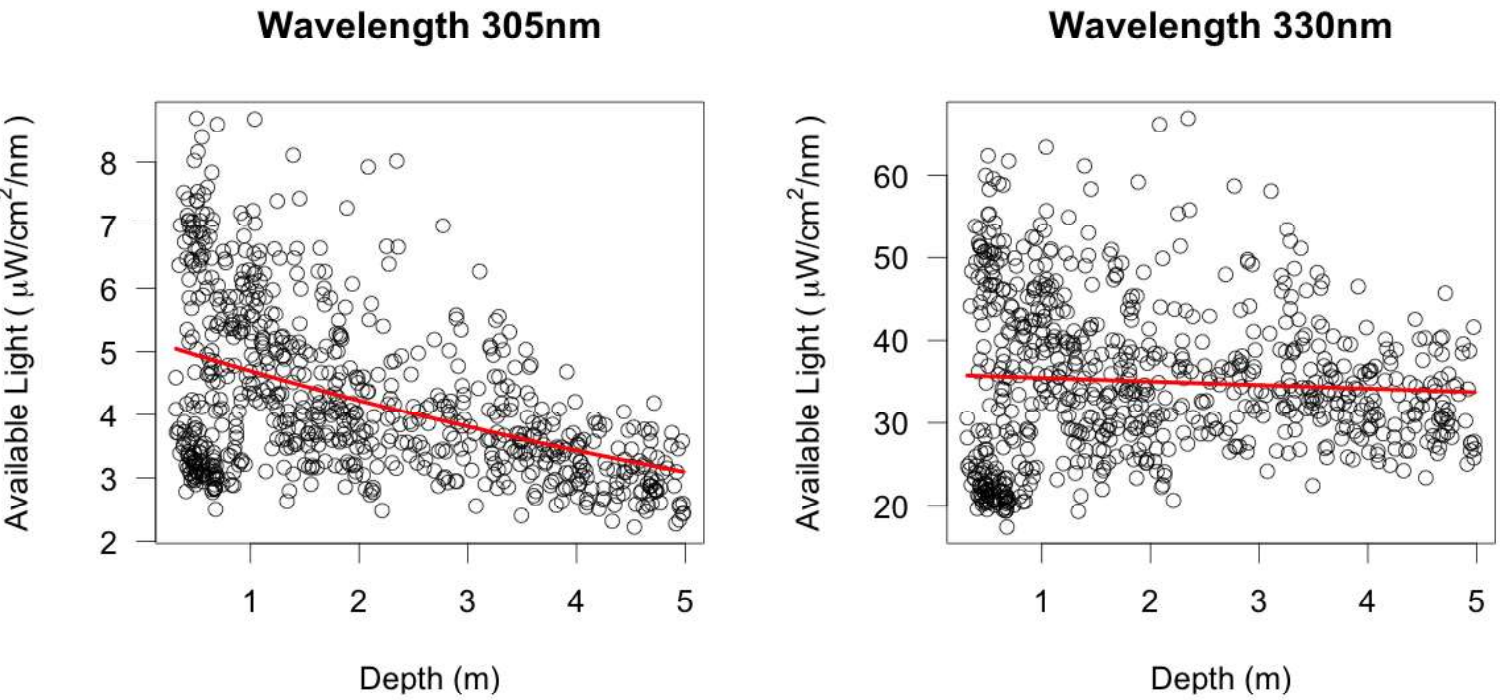

Wavelength $380 \mathrm{~nm}$

PAR
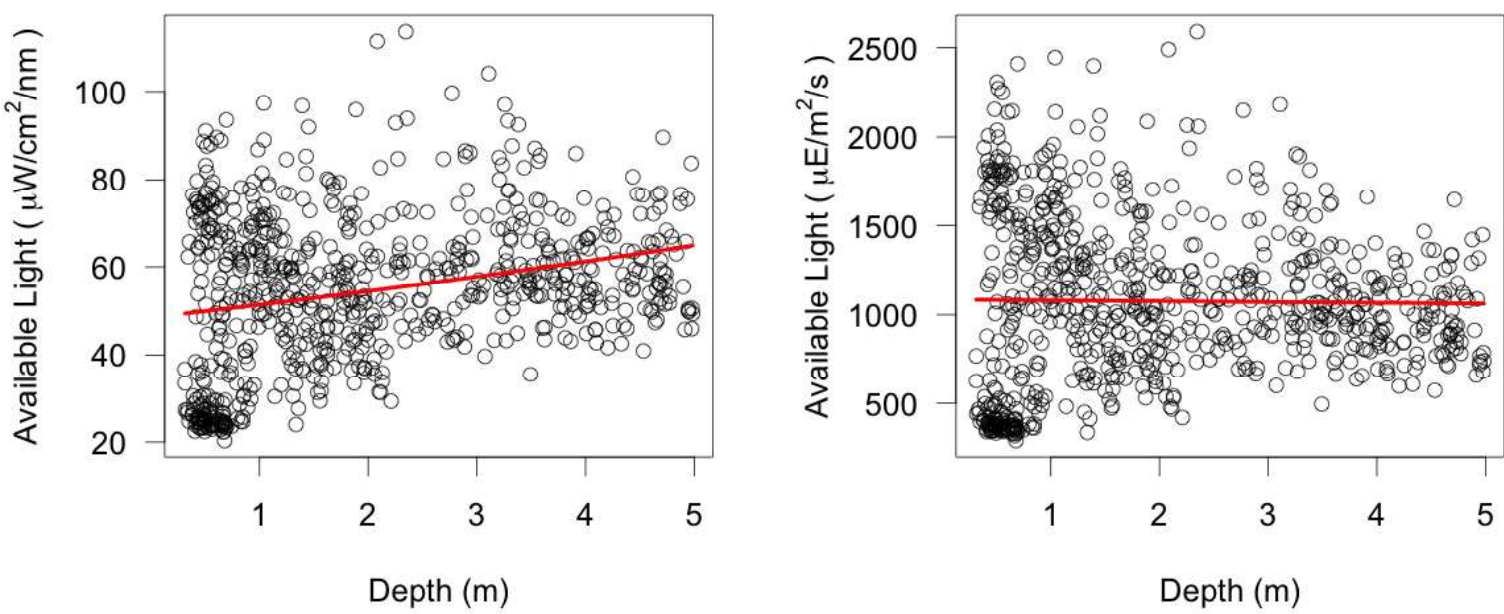

Figure 8: The amount of available light in surface to $5 \mathrm{~m}$ interval (upward profile) with the curve of the best fit depicted in red. The $(C, k)$ values are $(5.21,0.1)$ for $305 \mathrm{~nm},(31.95,0.01)$ for $330 \mathrm{~nm}$, $(48.52,0.06)$ for $380 \mathrm{~nm}$, and $(1085.56,0.004)$ for PAR. 
Wavelength $305 \mathrm{~nm}$

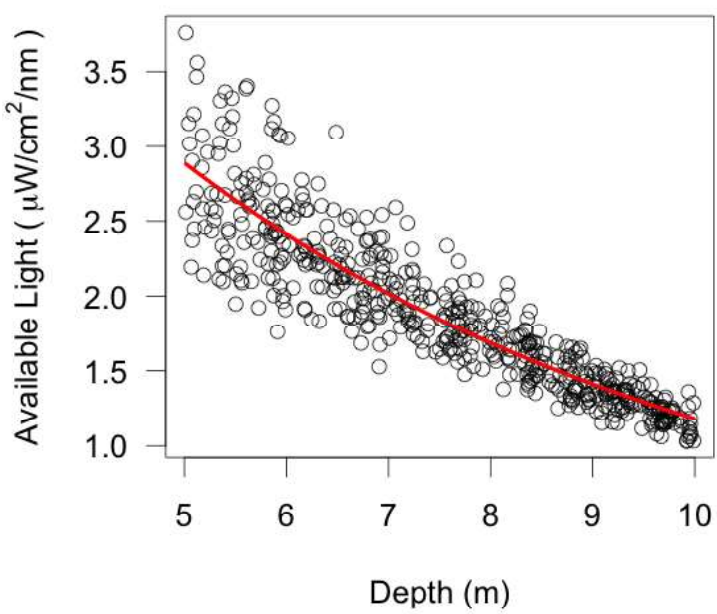

Wavelength 380nm

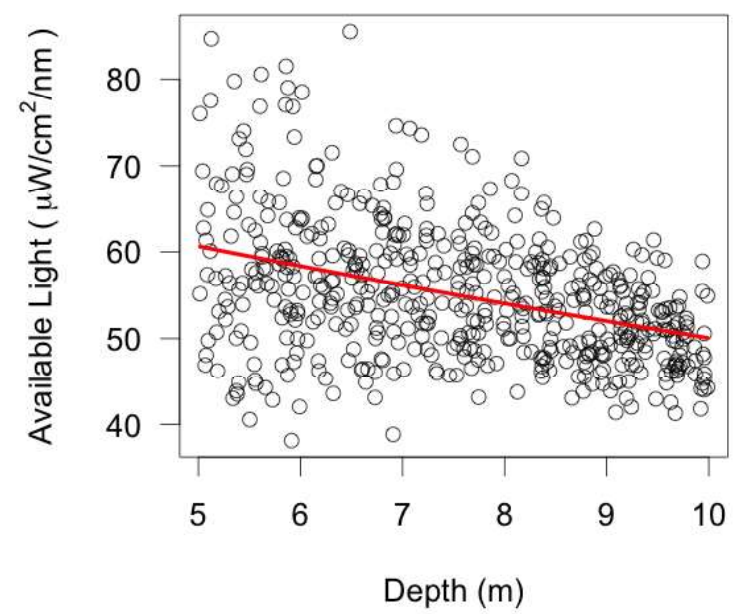

Wavelength $330 \mathrm{~nm}$

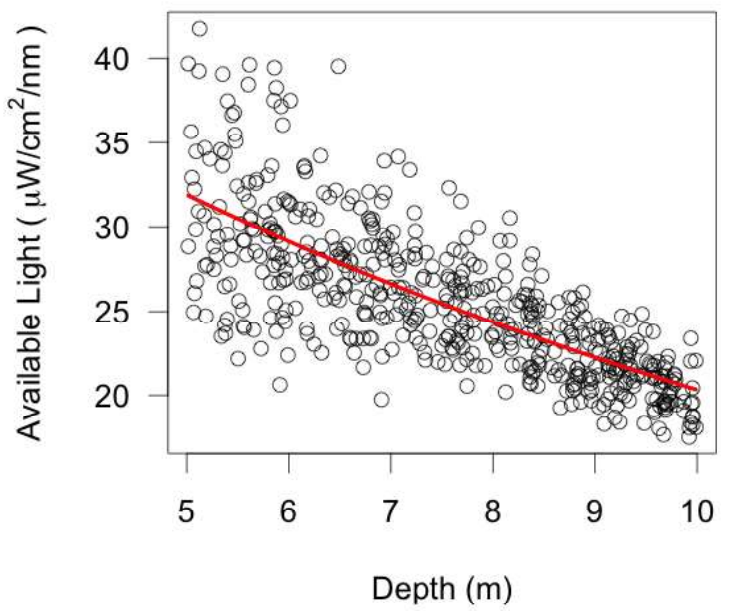

PAR

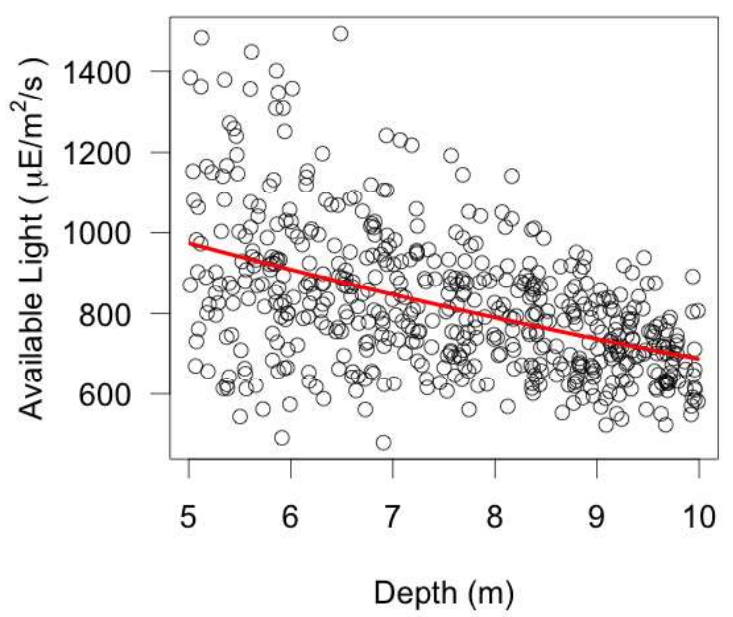

Figure 9: The amount of available light in $5 \mathrm{~m}$ to $10 \mathrm{~m}$ interval (upward profile) with the curve of the best fit depicted in red. The $(C, k)$ values are $(7.08,0.18)$ for $305 \mathrm{~nm},(50.05,0.1)$ for $330 \mathrm{~nm}$, $(73.44,0.04)$ for $380 \mathrm{~nm}$, and $(1378.18,0.07)$ for PAR. 


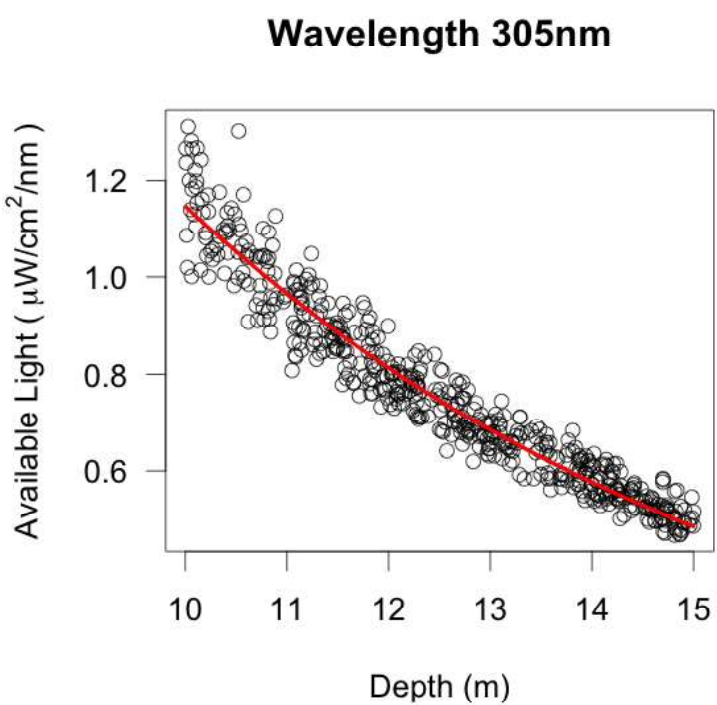

Wavelength $380 \mathrm{~nm}$

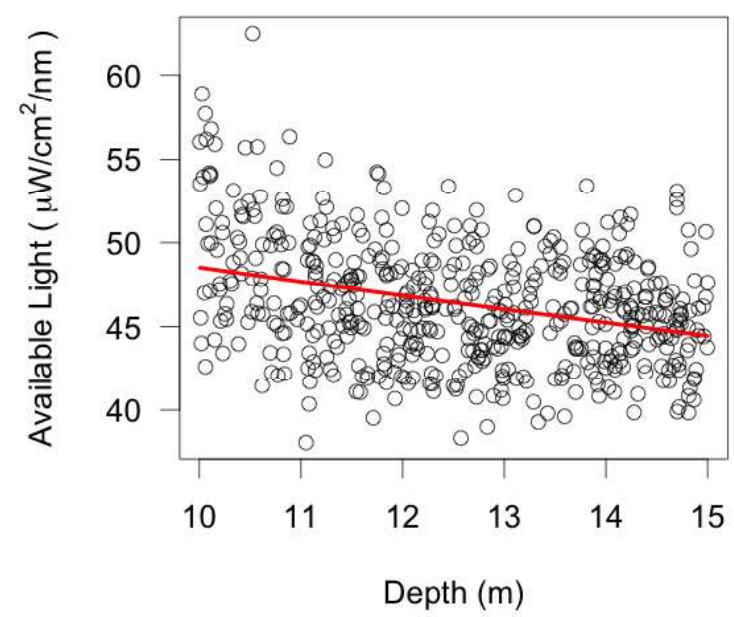

Wavelength $330 \mathrm{~nm}$

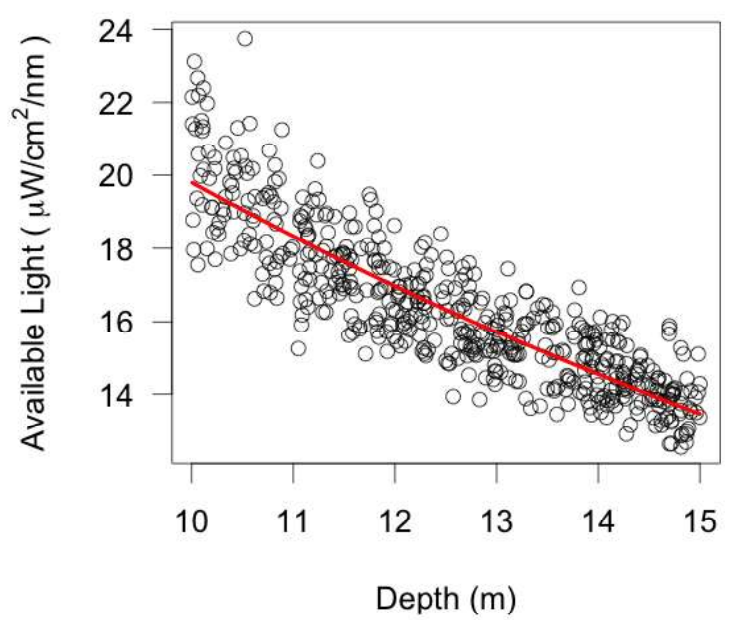

PAR

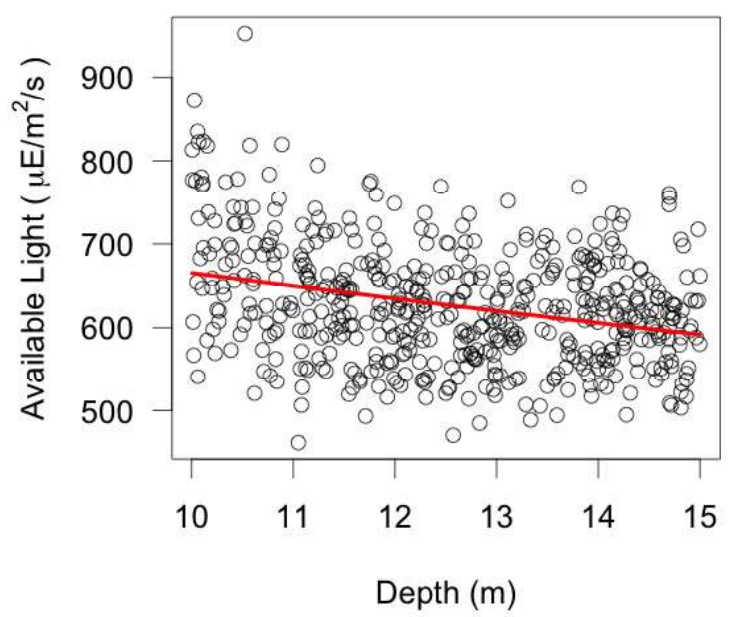

Figure 10: The amount of available light in $10 \mathrm{~m}$ to $15 \mathrm{~m}$ interval (upward profile) with the curve of the best fit depicted in red. The $(C, k)$ values are $(6.40,0.17)$ for $305 \mathrm{~nm},(42.80,0.08)$ for $330 \mathrm{~nm},(45.78,0.02)$ for $380 \mathrm{~nm}$, and $(841.42,0.02)$ for PAR. 
Wavelength $305 \mathrm{~nm}$

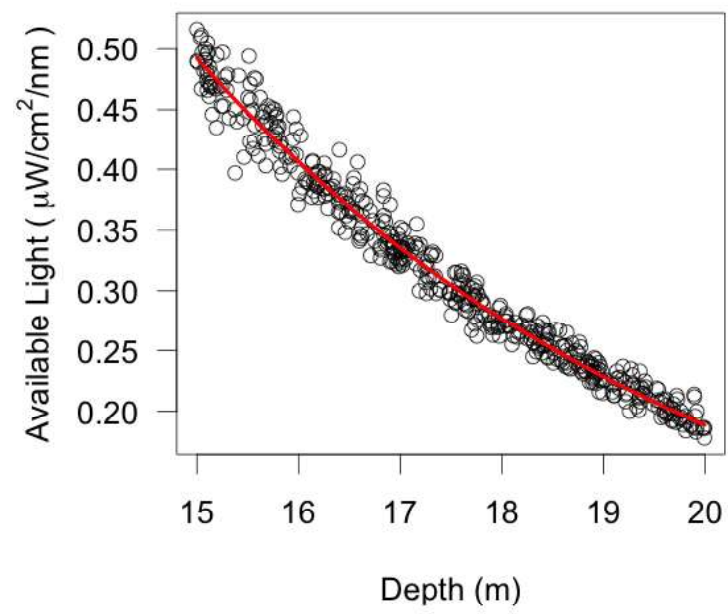

Wavelength 380nm

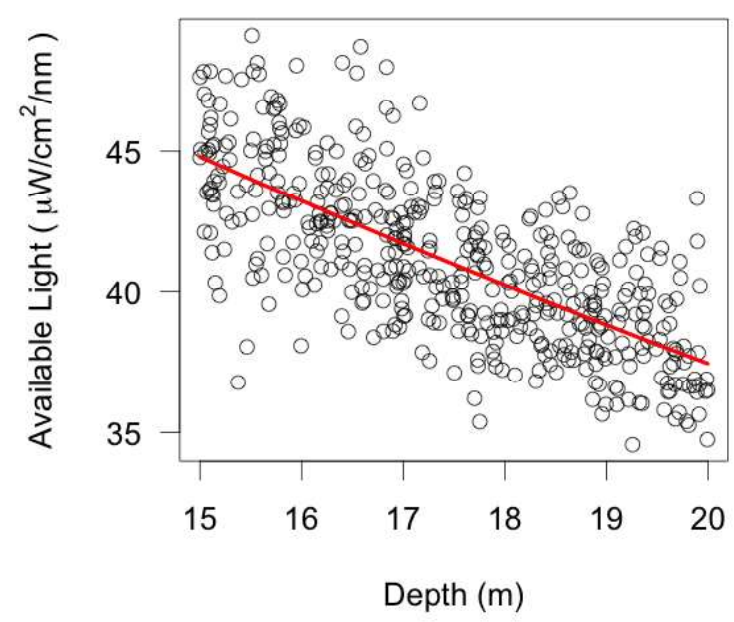

Wavelength $330 \mathrm{~nm}$

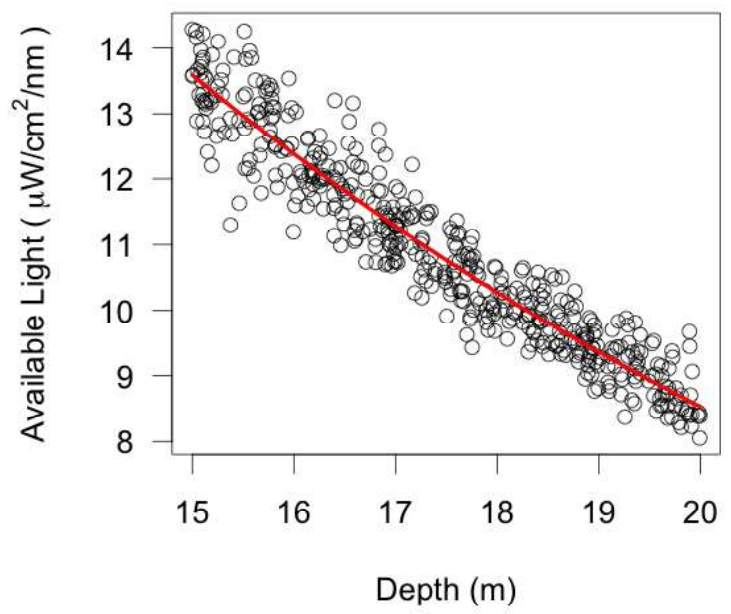

PAR

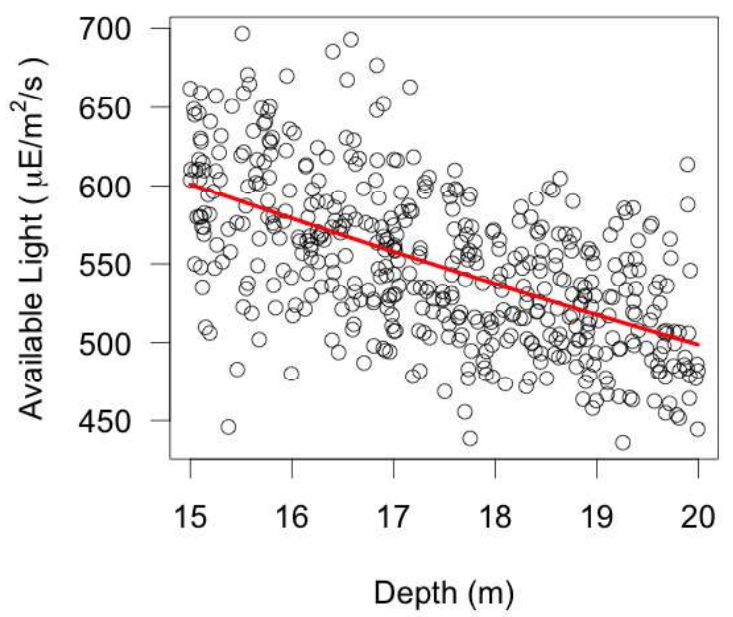

Figure 11: The amount of available light in $15 \mathrm{~m}$ to $20 \mathrm{~m}$ interval (upward profile) with the curve of the best fit depicted in red. The $(C, k)$ values are $(8.75,0.19)$ for $305 \mathrm{~nm},(54.96,0.09)$ for $330 \mathrm{~nm},(76.64,0.04)$ for $380 \mathrm{~nm}$, and $(1051.44,0.04)$ for PAR. 
Wavelength $305 \mathrm{~nm}$

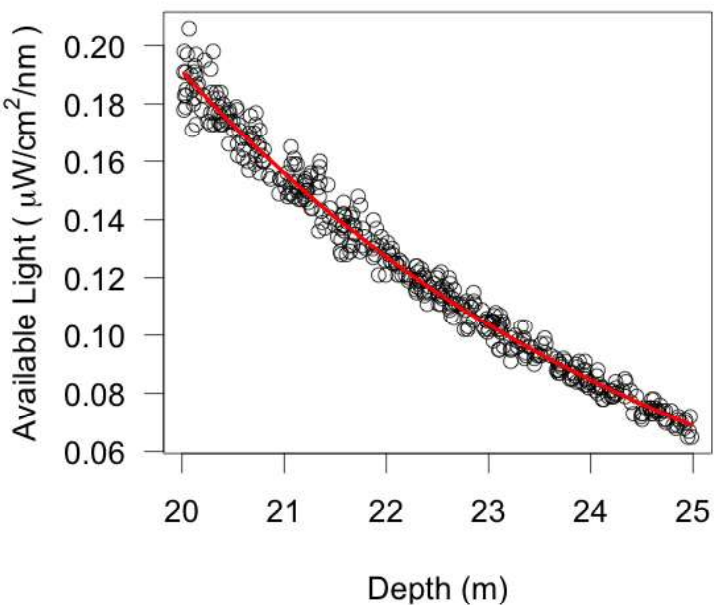

Wavelength $380 \mathrm{~nm}$

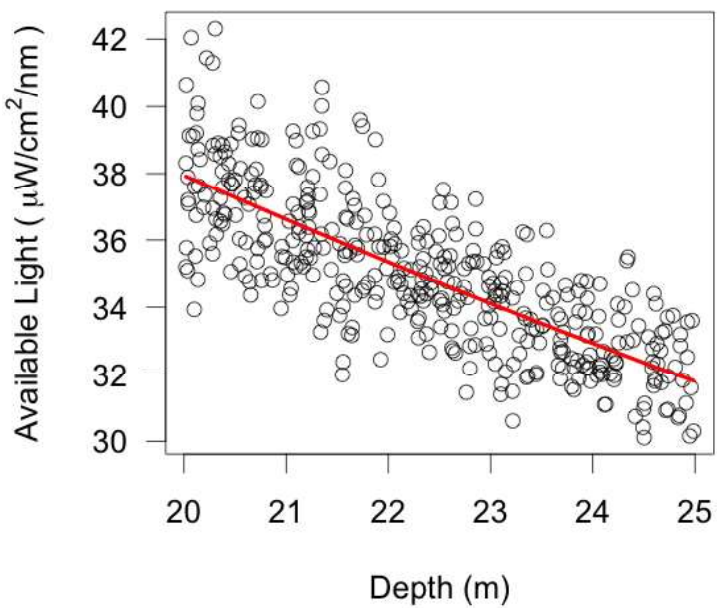

Wavelength $330 \mathrm{~nm}$

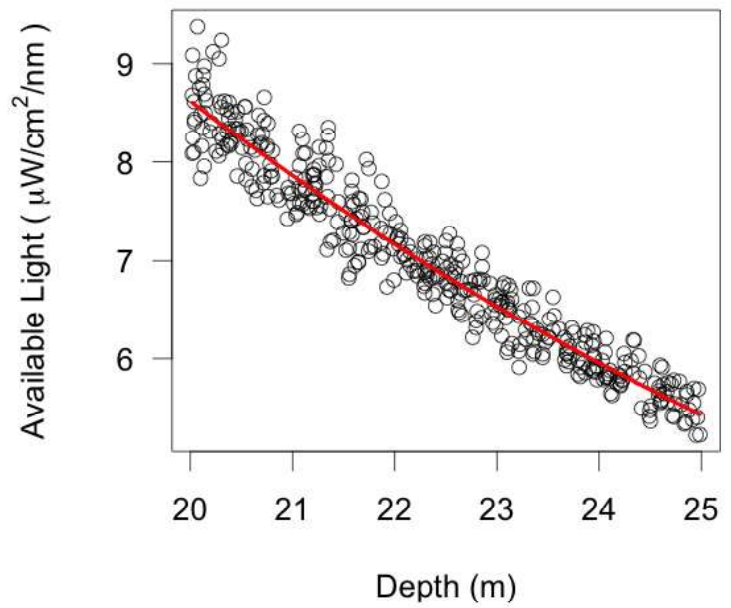

PAR

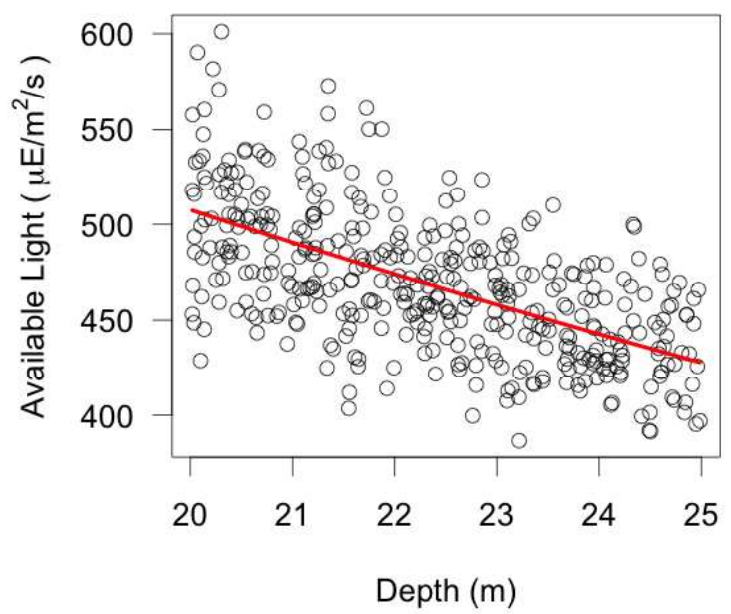

Figure 12: The amount of available light in $20 \mathrm{~m}$ to $25 \mathrm{~m}$ interval (upward profile) with the curve of the best fit depicted in red. The $(C, k)$ values are $(11.34,0.20)$ for $305 \mathrm{~nm},(54.91,0.09)$ for $330 \mathrm{~nm},(77.07,0.04)$ for $380 \mathrm{~nm}$, and $(1007.05,0.03)$ for PAR. 
Wavelength $305 \mathrm{~nm}$

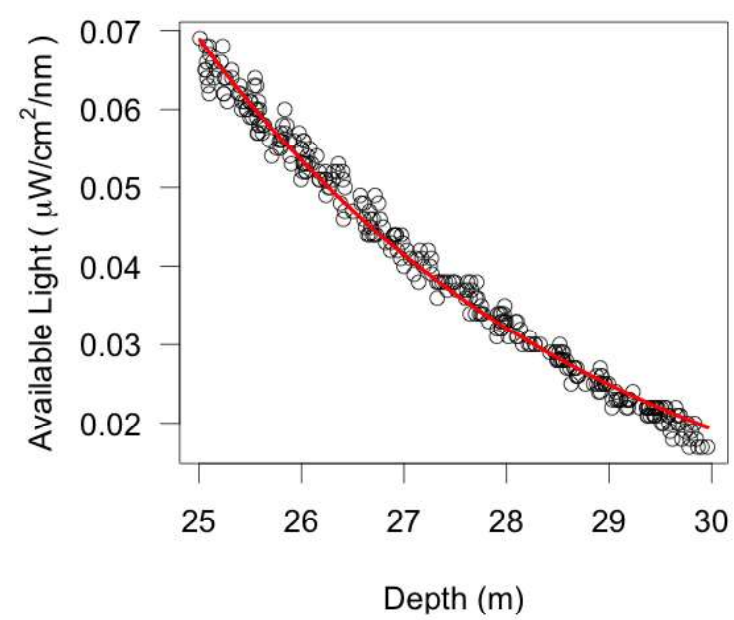

Wavelength 380nm

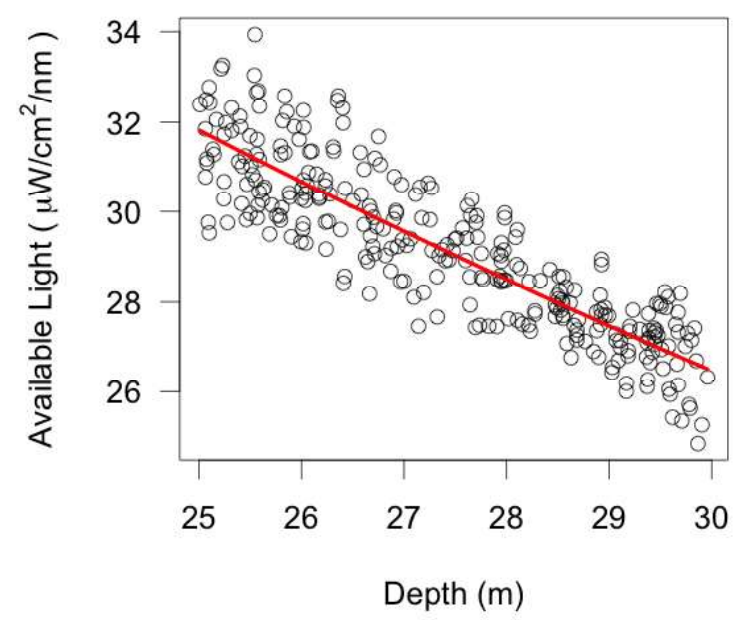

Wavelength $330 \mathrm{~nm}$

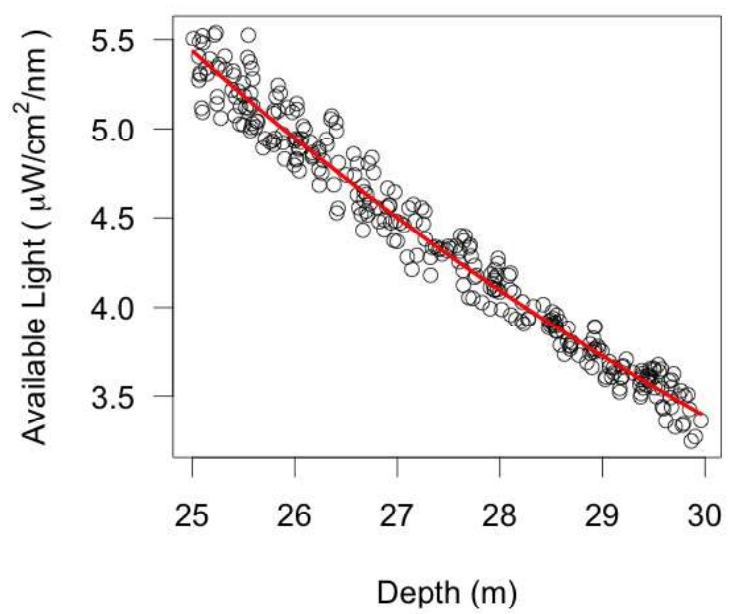

PAR

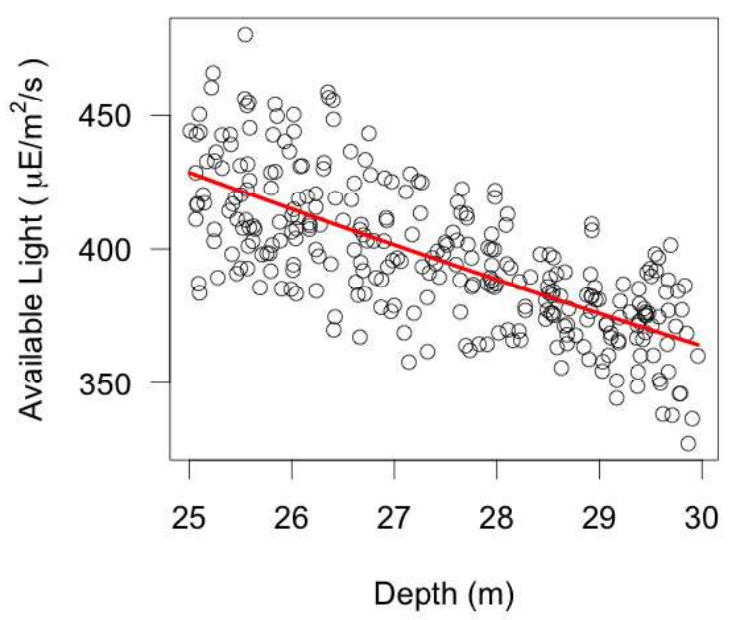

Figure 13: The amount of available light in $25 \mathrm{~m}$ to $30 \mathrm{~m}$ interval (upward profile) with the curve of the best fit depicted in red. The $(C, k)$ values are $(40.40,0.25)$ for $305 \mathrm{~nm},(57.79,0.09)$ for $330 \mathrm{~nm},(79.87,0.04)$ for $380 \mathrm{~nm}$, and $(972.91,0.03)$ for PAR. 


\section{Appendix II - Tables}

\begin{tabular}{|c|c|c|c|c|c|c|c|c|}
\hline \multicolumn{9}{|c|}{ Downward Profile } \\
\hline \multirow{2}{*}{ Depth } & \multicolumn{2}{|c|}{$305 \mathrm{~nm}$} & \multicolumn{2}{c|}{$330 \mathrm{~nm}$} & \multicolumn{2}{c|}{$380 \mathrm{~nm}$} & \multicolumn{2}{c|}{ PAR } \\
\cline { 2 - 10 } & $C$ & $k$ & $C$ & $k$ & $C$ & $k$ & $C$ & $k$ \\
\hline $0 \mathrm{~m}-5 \mathrm{~m}$ & 8.34 & 0.32 & 57.62 & 0.23 & 87.58 & 0.19 & 2174.78 & 0.34 \\
\hline $5 \mathrm{~m}-10 \mathrm{~m}$ & 4.56 & 0.16 & 31.00 & 0.07 & 40.44 & 0.02 & 611.70 & 0.04 \\
\hline $10 \mathrm{~m}-15 \mathrm{~m}$ & 4.49 & 0.17 & 30.68 & 0.07 & 40.19 & 0.02 & 526.11 & 0.03 \\
\hline $15 \mathrm{~m}-20 \mathrm{~m}$ & 7.07 & 0.12 & 11.51 & 0.02 & 10.47 & -0.06 & 55.37 & -0.11 \\
\hline $20 \mathrm{~m}-25 \mathrm{~m}$ & 12.50 & 0.21 & 56.60 & 0.10 & 80.67 & 0.09 & 1119.07 & 0.04 \\
\hline $25 \mathrm{~m}-30 \mathrm{~m}$ & 27.57 & 0.24 & 37.43 & 0.08 & 46.90 & 0.02 & 229.54 & 0.01 \\
\hline
\end{tabular}

Table 1: The values of the constant $(C)$ and the rate of decay $(k)$ for the function of the best fit for a given depth interval of the downward profile.

\begin{tabular}{|c|c|c|c|c|c|c|c|c|}
\hline \multicolumn{9}{|c|}{ Upward Profile } \\
\hline \multirow{2}{*}{ Depth } & \multicolumn{2}{|c|}{$305 \mathrm{~nm}$} & \multicolumn{2}{c|}{$330 \mathrm{~nm}$} & \multicolumn{2}{c|}{$380 \mathrm{~nm}$} & \multicolumn{2}{c|}{ PAR } \\
\cline { 2 - 10 } & $C$ & $k$ & $C$ & $k$ & $C$ & $k$ & $C$ & $k$ \\
\hline $0 \mathrm{~m}-5 \mathrm{~m}$ & 5.21 & 0.1 & 31.95 & 0.01 & 48.52 & -0.06 & 1085.56 & 0.004 \\
\hline $5 \mathrm{~m}-10 \mathrm{~m}$ & 7.08 & 0.18 & 50.05 & 0.1 & 73.44 & 0.04 & 1378.18 & 0.07 \\
\hline $10 \mathrm{~m}-15 \mathrm{~m}$ & 6.40 & 0.17 & 42.80 & 0.08 & 45.78 & 0.02 & 841.42 & 0.02 \\
\hline $15 \mathrm{~m}-20 \mathrm{~m}$ & 8.75 & 0.19 & 54.96 & 0.09 & 76.64 & 0.04 & 1051.44 & 0.04 \\
\hline $20 \mathrm{~m}-25 \mathrm{~m}$ & 11.34 & 0.20 & 54.91 & 0.09 & 77.07 & 0.04 & 1007.05 & 0.03 \\
\hline $25 \mathrm{~m}-30 \mathrm{~m}$ & 40.40 & 0.25 & 57.79 & 0.09 & 79.87 & 0.04 & 972.91 & 0.03 \\
\hline
\end{tabular}

Table 2: The values of the constant $(C)$ and the rate of decay $(k)$ for the function of the best fit for a given depth interval of the upward profile. 